\title{
Stress responsiveness of the pituitary-interrenal axis during early life stages of common carp (Cyprinus carpio)
}

\author{
A J H X Stouthart, E C H E T Lucassen, F J C van Strien, \\ P H M Balm, R A C Lock and S E Wendelaar Bonga
}

Department of Animal Physiology, Faculty of Science, University of Nijmegen, Toernooiveld 1, 6525 ED Nijmegen, The Netherlands

(Requests for offprints should be addressed to A J H X Stouthart)

\begin{abstract}
Whole-body levels of ACTH, $\alpha-\mathrm{MSH}$ and cortisol in eggs and larvae of the common carp (Cyprinus carpio) were determined periodically up until $168 \mathrm{~h}$ after fertilisation. ACTH, $\alpha-\mathrm{MSH}$ and cortisol immunoreactivity was detected in unfertilised eggs, and endogenous production of ACTH and $\alpha-\mathrm{MSH}$ was observed $24 \mathrm{~h}$ after fertilisation and that of cortisol $36 \mathrm{~h}$ after fertilisation. ACTH immunoreactivity reached peak levels before hatching (56-72 h after fertilisation) and remained relatively stable thereafter, while $\alpha-\mathrm{MSH}$ immunoreactivity started to increase after hatching. At $36 \mathrm{~h}$ after fertilisation, wholebody cortisol levels increased rapidly reaching peak levels at the end of hatching (72 h after fertilisation), remaining stable until the end of the experiment. From $50 \mathrm{~h}$ after fertilisation onwards, embryos and larvae increased their whole-body cortisol levels when subjected to handling (mechanical pressure during egg stage or netting during the larval stage). It is concluded that the pituitaryinterrenal axis in carp is fully functional at the time of hatching. No indications of a stress non-responsive period after hatching were observed.
\end{abstract}

To characterise ACTH and $\alpha-\mathrm{MSH}$ immunoreactivities in carp larvae, whole-body homogenates were analysed by HPLC, with pituitary homogenates of adult carp serving as a reference. ACTH and $\alpha-\mathrm{MSH}$ immunoreactivity in carp larvae homogenates consisted of three and two products respectively. HPLC of adult carp pituitaries revealed the presence of two ACTH immunoreactive products, which may represent a phosphorylated and a non-phosphorylated ACTH variant, while the three $\alpha-\mathrm{MSH}$ peaks most likely represent des-acetylated, mono-acetylated and di-acetylated $\alpha-\mathrm{MSH}$, the latter being the predominant form. In carp larvae, however, one of the ACTH immunoreactive products co-eluted with the non-phosphorylated ACTH, while the two $\alpha-\mathrm{MSH}$ products identified co-eluted with des-acetylated and mono-acetylated $\alpha-\mathrm{MSH}$, indicating that POMC processing at this stage of development is different from prohormone processing in adult fish.

Journal of Endocrinology (1998) 157, 127-137

\section{Introduction}

The hypothalamus-pituitary-interrenal (HPI) axis of fish is crucial for the adaptation of these animals to environmental challenges. Adrenocorticotrophic hormone $(\mathrm{ACTH})$, which is produced in the pars distalis of the pituitary gland, is considered the major corticotrophic factor regulating the synthesis and release of cortisol (Balm et al. 1994, Wendelaar Bonga 1997). In tilapia (Oreochromis mossambicus), $\alpha$-melanocyte-stimulating hormone ( $\alpha$ $\mathrm{MSH}$ ), which is produced in the pars intermedia of the pituitary gland, exerts corticotrophic actions in vitro (Lamers et al. 1992). The interrenal corticosteroid cortisol has been shown to affect osmoregulation, energy metabolism, immune competence (Wendelaar Bonga 1997) and developmental processes, including hatching, growth and metamorphosis, in particular during stress (De Jesus et al.
1991, Yamano et al. 1991). The presence of cortisol has been demonstrated in eggs and larvae of various cichlid and salmonid species (De Jesus \& Hirano 1992, Hwang et al. 1992, Hwang \& Wu 1993, Barry et al. 1995). In unfertilised fish eggs, cortisol is already present because of maternal transfer during oogenesis (Feist et al. 1990), but endogenous cortisol production does not start before hatching (De Jesus et al. 1991, Hwang et al. 1992, Hwang \& Wu 1993, Barry et al. 1995, Sampath-Kumar et al. 1995). Studies on salmonid species have indicated that ACTH as well as $\alpha-M S H$ immunopositive cells are present in the pituitary glands of fish embryos (Naito et al. 1993, Saga et al. 1993), although the onset of production of these hormones and their concentrations have not yet been determined in these life stages.

In early stages of development, the HPI axis is activated during stress. Studies on salmonids using temperature 
shock and handling showed that the axis could be activated after hatching (Pottinger \& Mosuwe 1994, Barry et al. 1995). In other studies, toxic stressors were used to induce a stress response. Stouthart et al. (1998) showed that carp larvae exposed to PCB 126 evoked a stress response 3 days after hatching. Stephens et al. (1997) showed that turbot (Scophthalmus maximus) larvae exposed to the watersoluble fraction of crude oil increased their whole-body cortisol levels 2 days after hatching. In most of these studies, cortisol was the factor studied, whereas the role of ACTH and $\alpha-\mathrm{MSH}$ has received much less attention.

The aim of this paper is twofold. First to follow ACTH, $\alpha-\mathrm{MSH}$ and cortisol production during embryonic and larval development of carp (Cyprinus carpio) until $168 \mathrm{~h}$ after fertilisation, and, secondly, to determine at what time embryos and larvae can respond to handling stress by elevating whole-body cortisol levels.

\section{Materials and Methods}

In vitro fertilisation and incubation of eggs

Carp gametes were obtained from the common carp (Cyprinus carpio) as described by Oyen et al. (1991). Approximately 1200 eggs from one female were fertilised by sperm from one male and distributed among 20 Petri dishes. At $1 \mathrm{~min}$ after fertilisation, the Petri dishes, with fertilised eggs stuck to the bottom, were rinsed and transferred to 4-litre aquaria through which oxygenated UV-sterilised chemically defined water was pumped at 1 litre/h at $24^{\circ} \mathrm{C}$ under a $12 \mathrm{~h}$ light $/ 12 \mathrm{~h}$ darkness cycle. The water contained the following ions $(\mathrm{mmol} / \mathrm{l}): 0.06$ $\mathrm{KCl} ; 0.40 \mathrm{NaHCO}_{3} ; 0.20 \mathrm{MgSO}_{4} ; 0.80 \mathrm{CaCl}_{2}$. Eggs were considered dead when parts of the content turned opaque and white, or when the heart beat had stopped. Dead eggs were immediately removed to prevent fungal infection of the other eggs. The larvae were not fed during the experiment. Directly after fertilisation, 10 Petri dishes, each containing at least 30 eggs, were put in separate aquaria, and embryos or larvae were sampled at 12, 24, 36, $48,60,72,96,120,144$ and $168 \mathrm{~h}$ after fertilisation for determination of wet weight and hormone concentrations $(n=20)$. Two Petri dishes containing a total of at least 350 eggs were put in one aquarium for HPLC analysis, histology and immunology at $168 \mathrm{~h}$ after fertilisation. For the handling experiments, five Petri dishes, each containing at least 10 eggs, were put in one aquarium and used $50 \mathrm{~h}$ after fertilisation. Three Petri dishes (at least 150 eggs per dish) were kept in separate aquaria to carry out handling experiments with larvae at 72, 96 and $120 \mathrm{~h}$ after fertilisation. This protocol was repeated five times, yielding six determinations per treatment.

\section{Histology}

At $168 \mathrm{~h}$ after fertilisation, larvae were collected for light microscopical examination. After fixation in Bouin's solution, dehydration, and embedding in paraffin, sagittal sections were cut at $5 \mu \mathrm{m}$ thickness. An immunocytochemical method using antisera raised in rabbits against human ACTH(1-24) (this antiserum also detects melanotropes; van Eys \& van den Oetelaar 1981) and $\alpha-$ MSH (van Zoest et al. 1989) was used to identify immunoreactive ACTH and $\alpha-\mathrm{MSH}$ cells.

\section{RIAs}

Concentrations of ACTH, $\alpha-\mathrm{MSH}$ and cortisol were determined in duplicate by RIA as described by Balm et al. (1994), van Zoest et al. (1989) and Balm et al. (1998) respectively. The ACTH antibody had negligible cross-reactivity with $\alpha-\mathrm{MSH}$. The $\alpha-\mathrm{MSH}$ antibody recognised des-acetylated, mono-acetylated and di-acetylated $\alpha-\mathrm{MSH}$ with similar sensitivity. Although we cannot exclude cross-reactivity with components in the homogenates, the cortisol antibody has marginal crossreactivity with 11 -deoxycortisol $(5 \cdot 9 \%)$, cortisone acetate $(0 \cdot 16 \%)$, cortisone $(2 \cdot 6 \%)$ and $17 \alpha$-hydroxyprogesterone $(0 \cdot 4 \%)$. The detection limit of the assay was per tube: $0.32 \mathrm{pg}$ ACTH, $2.5 \mathrm{pg} \alpha-\mathrm{MSH}$ and $4 \mathrm{pg}$ cortisol. The intra- and inter-assay coefficients of variation were 6 and $7 \%$ for ACTH, 5 and $11 \%$ for $\alpha-\mathrm{MSH}$, and 3 and $5 \%$ for cortisol respectively.

\section{Biochemistry}

To identify different ACTH and $\alpha-\mathrm{MSH}$ immunoreactive forms, 300 larvae (168 h after fertilisation) were homogenised in $1 \mathrm{ml}$ ice-cold $0.01 \mathrm{M} \mathrm{HCl}$ using a glass-to-glass Potter homogeniser. Membranes and particulate material were removed by centrifugation $(13000 \boldsymbol{g}, 10 \mathrm{~min}$; repeated three times). The peptides were separated by reverse-phase HPLC. Fractions were freeze-dried under vacuum (Speed-Vac Concentrator Savant; New Brunswick Scientific, Edison, UK) and redissolved in $150 \mu \mathrm{l}$ RIA buffer. ACTH and $\alpha-\mathrm{MSH}$ immunoreactivity were determined in duplicate by RIA.

\section{Development}

To determine wet weight, 20 eggs or larvae from each batch were collected at $0 \mathrm{~h}$ (unfertilised eggs), 12, 24, 36, 48,60 and $72 \mathrm{~h}$ (hatching at 56-72 h after fertilisation), 96, 120 and $144 \mathrm{~h}$ (yolk absorption completed) and $168 \mathrm{~h}$ after fertilisation. Eggs or larvae were frozen in a mixture of dry ice and methanol (approximately $-70{ }^{\circ} \mathrm{C}$ ), collected in preweighed vials and weighed. To these samples were added $200 \mu \mathrm{l}(0,12,24,36,48,72$ and $96 \mathrm{~h}$ after fertilisation) or $400 \mu \mathrm{l}(120,144$ and $168 \mathrm{~h}$ after fertilisation) $0.01 \mathrm{M}$ ice-cold $\mathrm{HCl}$, and the mixture was subsequently homogenised using a glass-toglass Potter homogeniser. Membranes and particulate 


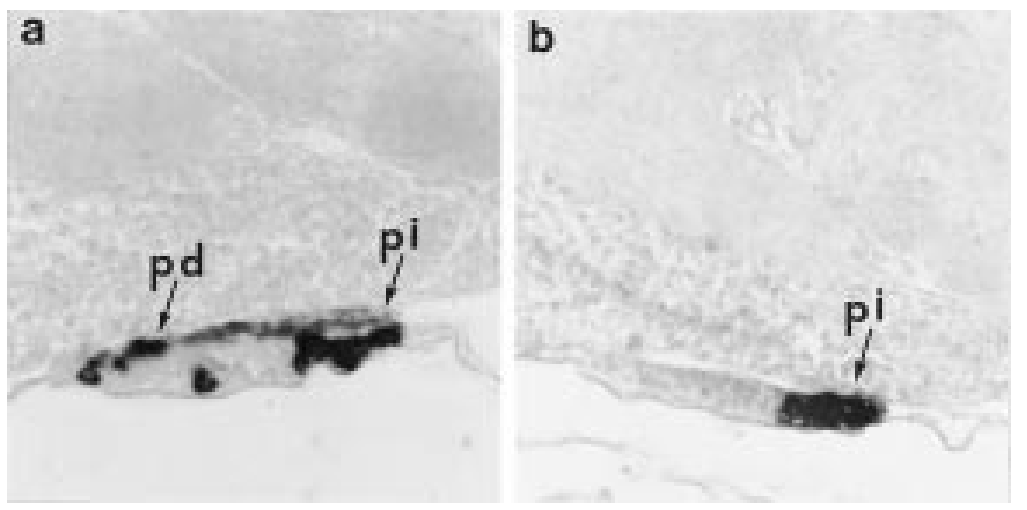

Figure 1 Mid-sagittal sections through the pituitary gland of $168 \mathrm{~h}$ old carp larvae (magnification $40 \times$ ). (a) Immunoreactive ACTH in cells located in the pars distalis (pd) and immunoreactive melanotropes in the pars intermedia (pi) of the pituitary. (b) Immunoreactive $\alpha-\mathrm{MSH}$ in cells located in the pars intermedia (pi) of the pituitary.

material were removed by centrifugation $(13000 \boldsymbol{g}$, $10 \mathrm{~min}$; repeated three times). Whole-body ACTH, $\alpha-\mathrm{MSH}$ and cortisol levels were determined in duplicate by RIA.

\section{Handling}

At $50 \mathrm{~h}$ after fertilisation a total of five Petri dishes were used. Embryos of one Petri dish were sampled at rest (time 0) by transferring them to a mixture of dry ice and methanol. Embryos of the remaining Petri dishes were mechanically disturbed by squeezing the eggshell slightly with forceps, inducing one tail movement of the embryo. This procedure started at rest (time 0) and was repeated after 1, 2, 3 and $4 \mathrm{~min}$. Embryos were sampled after 5, 30, 60 and $120 \mathrm{~min}$. A similar experiment was carried out with larvae at 72, 96, $120 \mathrm{~h}$ after fertilisation. At each of these time points 20 larvae were sampled at rest (time 0). The remaining larvae were netted for $1 \mathrm{~min}$ and distributed among four Petri dishes and subsequently sampled 5, 30, 60 and $120 \mathrm{~min}$ afterwards. To the samples were added $200 \mu \mathrm{l}$ (50, 72 and $96 \mathrm{~h}$ after fertilisation) or $400 \mu \mathrm{l}$ (120 after fertilisation) $0 \cdot 01 \mathrm{M}$ ice-cold $\mathrm{HCl}$, and the samples were subsequently homogenised. Whole-body levels of cortisol were determined in duplicate by RIA. This experiment was repeated five times, yielding six determinations.

\section{Statistical analysis}

Differences among variances were evaluated by the Bartlett test. Mann-Whitney tests were used to assess differences among means. In data presented in Fig. 4, means of the time point following directly after the lowest hormone value were tested. Statistical signifi- cance was accepted at $P<0 \cdot 05$. Data are expressed as means \pm S.E.M.

\section{Results}

\section{Histology}

Immunoreactive ACTH and $\alpha-\mathrm{MSH}$ cells in the pituitary of $168 \mathrm{~h}$ old carp larvae are shown in Fig. 1. At $168 \mathrm{~h}$ after fertilisation, immunoreactive ACTH could be identified in cells located in the distal lobe of the pituitary (Fig. 1a). ACTH immunopositivity was also observed in the melanotrope cells. Immunoreactive $\alpha-\mathrm{MSH}$ was specifically located in cells of the intermediate lobe of the pituitary (Fig. 1b).

\section{Biochemistry}

Dose-response competitive binding curves for standard ACTH, $\alpha-\mathrm{MSH}$ and cortisol extracts of carp eggs (48 h after fertilisation) and larvae (168 after fertilisation) are shown in Fig. 2. Serial dilutions of egg and larvae homogenates displaced radiolabelled ACTH, $\alpha-\mathrm{MSH}$ and cortisol from the antibody in parallel with dilutions of the standards used.

HPLC analyses of the ACTH and $\alpha-\mathrm{MSH}$ immunoreactivities in carp pituitary homogenates are shown in Fig. 3. ACTH was present as two products (peak A and $\mathrm{B})$, peak $\mathrm{B}$ being the predominant form. The $\alpha-\mathrm{MSH}$ immunograms from the adult carp pituitary homogenates demonstrated three peaks, designated des-acetylated, mono-acetylated and di-acetylated $\alpha$-MSH (Follénius et al. 1985). In carp larvae homogenates, three ACTH products were seen. Only one peak (termed $A^{\prime}$ ) was co-eluted with peak $A$ in the adult carp pituitary. Analysis 

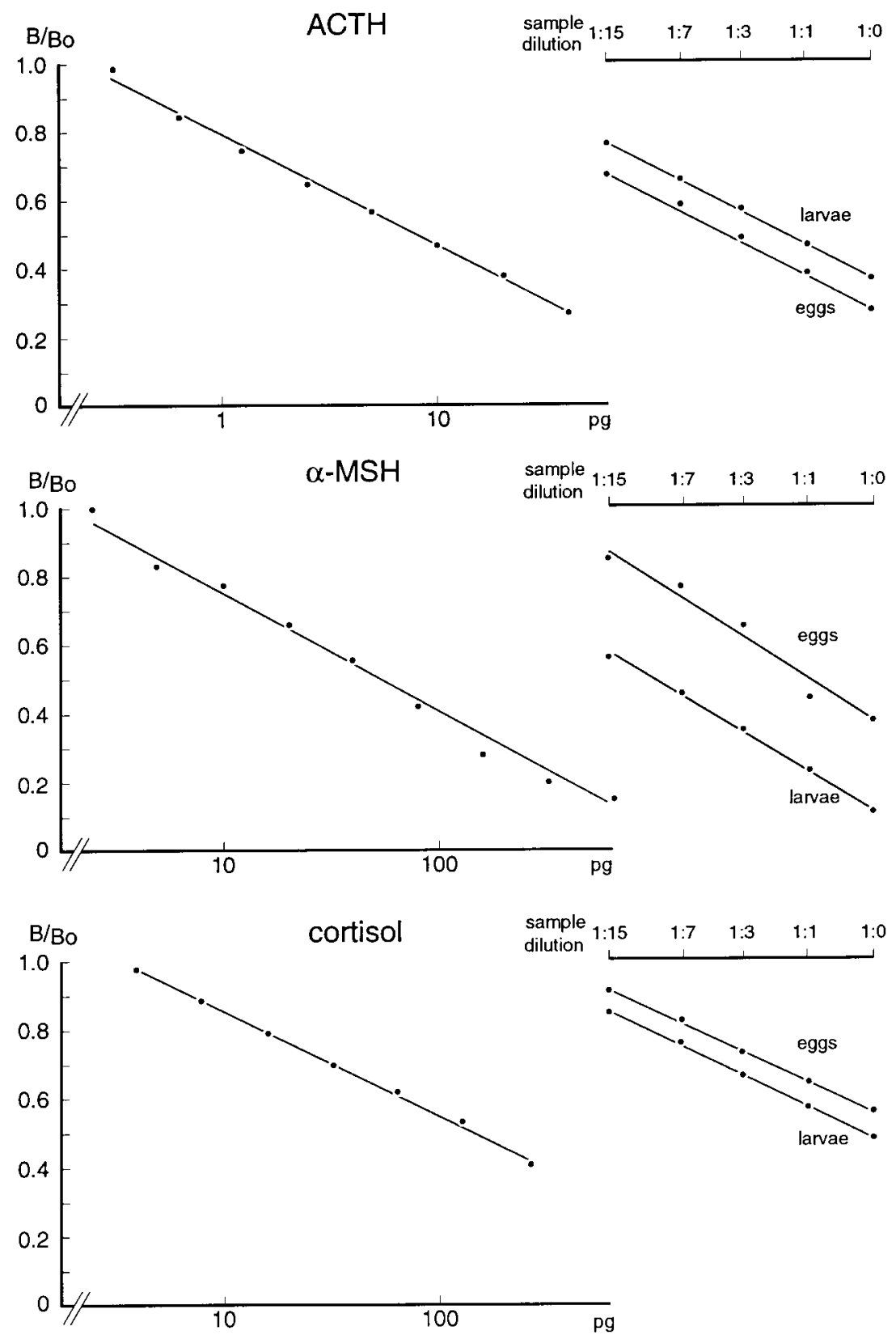

Figure 2 Competitive binding curves of $\mathrm{ACTH}, \alpha-\mathrm{MSH}$ and cortisol standards and dilution curves of $\mathrm{ACTH}, \alpha-\mathrm{MSH}$ and cortisol in homogenates of eggs (48 $\mathrm{h}$ after fertilisation) and larvae (168 $\mathrm{h}$ after fertilisation). $\mathrm{B} / \mathrm{B}_{\mathrm{o}}$, bound/free.

of the $\alpha-\mathrm{MSH}$ immunoreactivity in carp larvae homogenates revealed two products, co-eluted with des-acetylated and mono-acetylated $\alpha-\mathrm{MSH}$.

\section{Development}

The wet weight of 20 unfertilised eggs was $23.9 \pm 0.6 \mathrm{mg}$. Directly after fertilisation, it increased to $56 \cdot 4 \pm 2 \cdot 9 \mathrm{mg}$ and remained stable until hatching. Thereafter, the wet weight of 20 larvae decreased to $27.5 \pm 1.6 \mathrm{mg}$ and remained stable until $168 \mathrm{~h}$ after fertilisation. Whole-body immunoreactive ACTH, $\alpha-\mathrm{MSH}$ and cortisol levels during the first $168 \mathrm{~h}$ of carp development are shown in Fig. 4. ACTH immunoreactivity could be detected in unfertilised eggs $(t=0)$ and decreased until $24 \mathrm{~h}$ after fertilisation. From $24 \mathrm{~h}$ after fertilisation, ACTH 


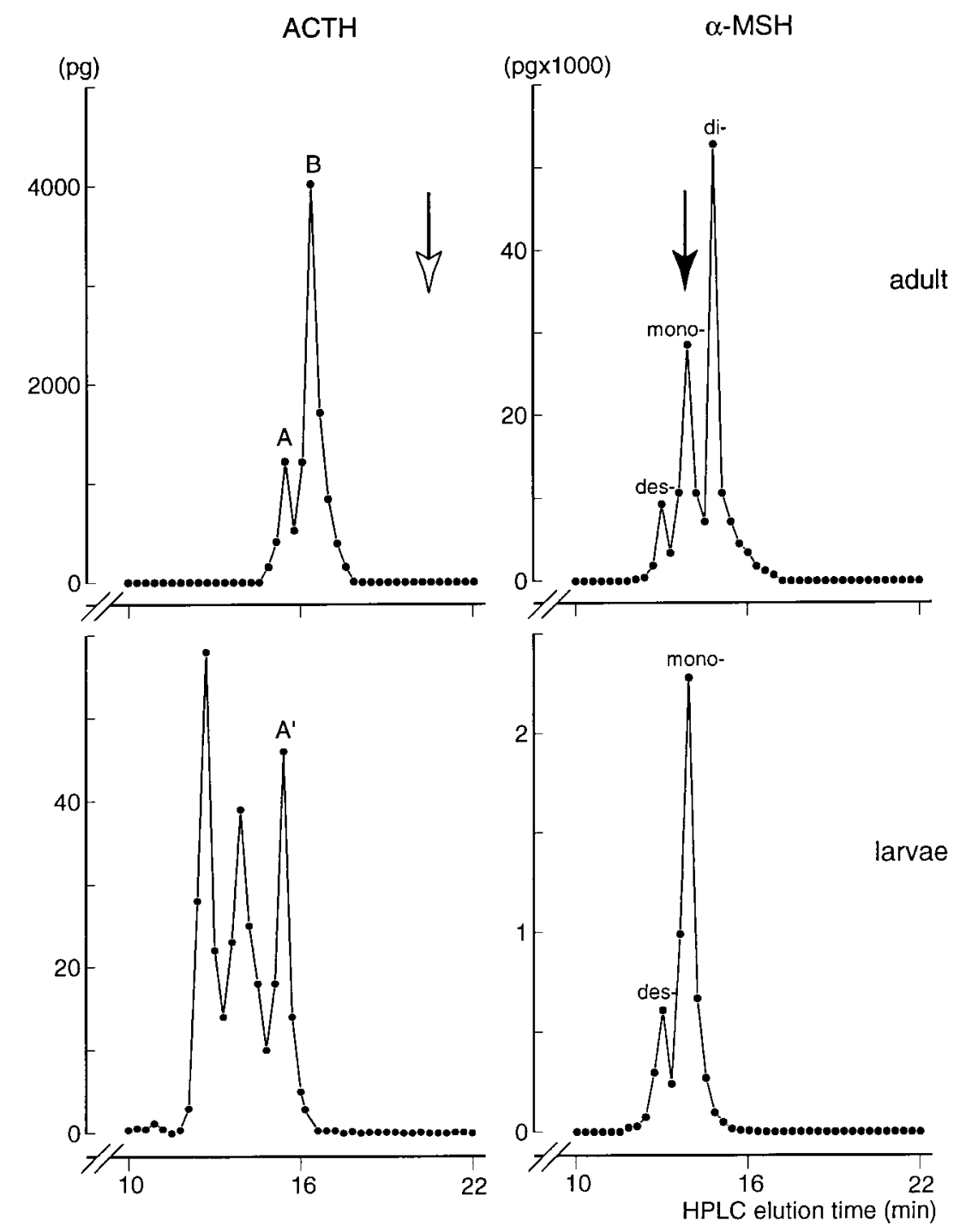

Figure 3 HPLC immunograms of adult carp pituitaries and whole-body carp larvae homogenates (168 h after fertilisation). $\bullet$, Elution profiles of ACTH and $\alpha-\mathrm{MSH}$. Open and closed arrows indicate the elution position of the human $\mathrm{ACTH}(1-39)$ standard and $\alpha-\mathrm{MSH}$ standard respectively. Between 10 and $22 \mathrm{~min}, 0 \cdot 3 \mathrm{~min}$ fractions were collected.

immunoreactivity increased significantly $(P<0 \cdot 05)$. In particular, before and during hatching $(56-72 \mathrm{~h}$ after fertilisation), ACTH immunoreactivity increased markedly. After hatching, ACTH levels decreased. Immunoreactivity of $\alpha-\mathrm{MSH}$ could be detected in unfertilised eggs $(t=0)$; it decreased until $24 \mathrm{~h}$ after fertilisation, and then increased slightly but significantly $(P<0 \cdot 001)$. After hatching, whole-body $\alpha-\mathrm{MSH}$ levels rapidly increased further and stabilised. In unfertilised eggs, high levels of cortisol were present, which decreased over the $36 \mathrm{~h}$ post-fertilisation period. After that, whole-body cortisol levels significantly
$(P<0 \cdot 001)$ increased to a steady level at $72 \mathrm{~h}$ (end of hatching).

\section{Handling}

Whole-body cortisol levels of controls and stressed carp embryos and larvae at 50, 72, 96 and $120 \mathrm{~h}$ after fertilisation are shown in Fig. 5. Embryos $(50 \mathrm{~h}$ after fertilisation; $6 \mathrm{~h}$ before hatching) responded $5 \mathrm{~min}$ after handling with a significant $(P<0 \cdot 01)$ increase in whole-body cortisol levels, which returned to control levels within $30 \mathrm{~min}$. 


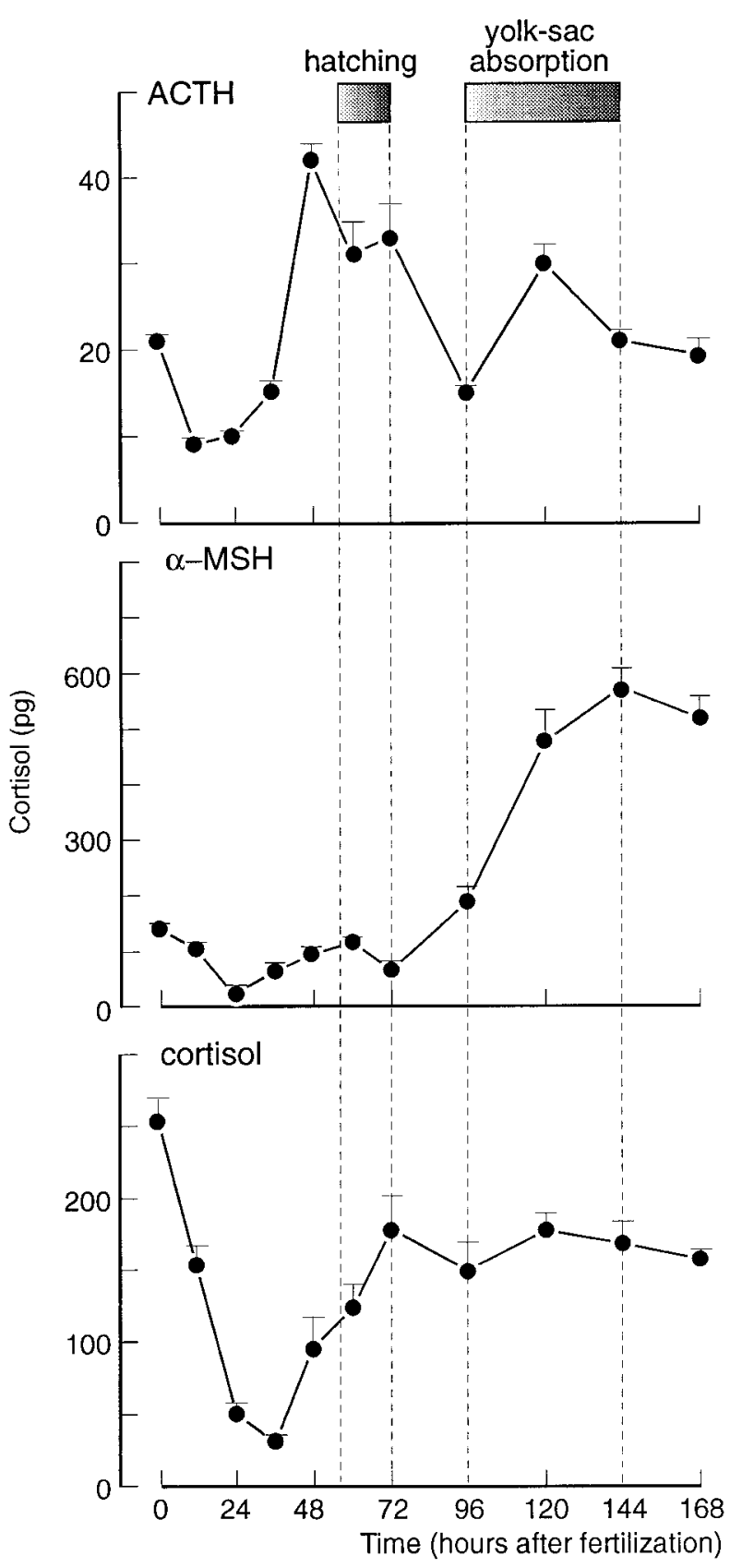

Figure 4 Changes in $\mathrm{ACTH}, \alpha-\mathrm{MSH}$ and cortisol immunoreactivity (in pg per 20 eggs or larvae) during the early development of carp. Data are expressed as means \pm S.E.M. $(n=6)$.

Directly after hatching (72 h fertilisation), larvae subjected to handling had significantly $(P<0 \cdot 01)$ increased cortisol levels at 5, 30 and $60 \mathrm{~min}$, decreasing to control levels after $120 \mathrm{~min}$. Larvae subjected to handling at 96 or $120 \mathrm{~h}$ after fertilisation had significantly increased whole-body cortisol levels compared with controls at respectively $5(P<0 \cdot 01)$, or 5 and $30 \mathrm{~min}(P<0 \cdot 05)$, and returned to control levels after 30 or $60 \mathrm{~min}$ respectively.

\section{Discussion}

\section{Characterisation of $A C T H$ and $a-M S H$}

As in tilapia (Balm et al. 1994), two immunoreactive forms of $\mathrm{ACTH}$ (termed A and B) were found in the pituitary of adult carp. The antiserum used has been demonstrated to detect ACTH molecules in a variety of (non-mammalian) vertebrate species (Dores et al. 1993). The immunoreactive ACTH products in carp were eluted earlier than the human ACTH standard, which has also been demonstrated for tilapia (Balm et al. 1994). In the latter study it was demonstrated that the two ACTH immunoreactive products were equipotent in stimulating cortisol release from the interrenal cells, their potency being similar to that of human ACTH. We therefore conclude that the two products identified in the present study represent carp ACTH. Consistent with this, Hon \& Ng (1986) showed that several fractions of carp pituitary glands separated via CM-cellulose chromatography possessed ACTH-like immunoreactivity, whereas only two fractions were bioactive, as evidenced by dose-related stimulation of corticosterone production from isolated rat adrenal cells. Tran et al. (1989) found two immunoreactive ACTH products in the cyprinid goldfish (Carassius auratus). Also in human pituitaries, two distinct, steroidogenically equipotent forms of ACTH were isolated and purified (Bennett et al. 1983). This latter study identified the more polar form of ACTH as a phosphorylated form, whereas quantitatively the non-phosphorylated ACTH was most abundant. Possibly, the two products found in adult carp pituitaries also represent a non-phosphorylated (A) and a phosphorylated (B) form of ACTH, as discussed previously for tilapia (Balm et al. 1994). The finding that teleost ACTH, but not $\alpha-\mathrm{MSH}$, is eluted at different positions from their human counterparts most likely relates to the considerable dissimilarities in amino acid sequence between the hormones, which is almost exclusively restricted to the corticotrophin-like intermediate lobe peptide (CLIP) moiety. Three forms of $\alpha$-MSH were found in the adult carp pituitary, i.e. des-acetylated, mono-acetylated and di-acetylated. These $\alpha-\mathrm{MSH}$ forms were described previously for the intermediate lobes of the cyprinids Cyprinus carpio and Carassius auratus by Follénius et al. (1985), and the cichlid tilapia by Lamers et al. (1991) and Balm et al. (1994). In agreement with their findings, the di-acetylated $\alpha-\mathrm{MSH}$ was most abundant in the melanotropes of our carp. Because no literature is available on immunoreactive forms of ACTH and $\alpha-\mathrm{MSH}$ during the early life stages of the common carp and other teleosts, we compared data with the HPLC profiles of pituitaries obtained from adult carp pituitaries. The analysis of $168 \mathrm{~h}$ 

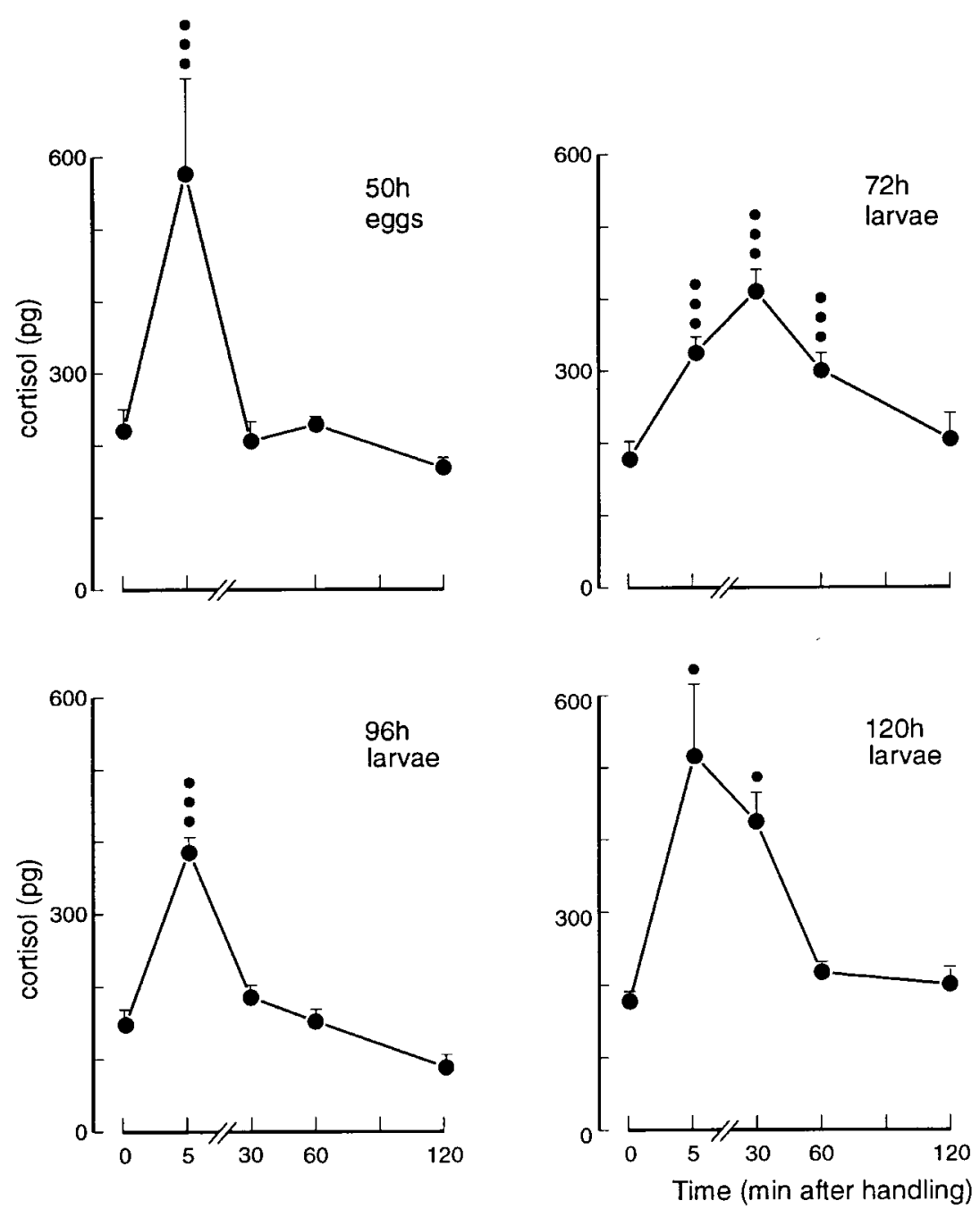

Figure 5 Changes in cortisol immunoreactivity at 5, 30,60 and 120 min after handling stress during different stages of the early development of carp (pg per 20 eggs or larvae): $50 \mathrm{~h}$ after fertilisation (before hatching); $72 \mathrm{~h}$ after fertilisation (directly after hatching); 96 and $120 \mathrm{~h}$ after fertilisation. Data are expressed as means \pm S.E.M. $(n=6)$.

old carp larvae revealed three ACTH immunoreactive peaks. One product $\left(\mathrm{A}^{\prime}\right)$, co-eluted with peak $A$ in the adult carp pituitary, may represent the nonphosphorylated form of ACTH. Although the two other peaks have not been identified, they could either originate from a larval type of corticotrope as present in mammals (Perez et al. 1997) or they could reflect different proopiomelanocortin processing in embryonal and mature corticotropes. The ACTH antibody used in our experiments showed a marginal cross-reactivity with CLIP in other vertebrates ( $\mathrm{R} M$ Dores, personal communication) but negligible cross-reactivity with tilapia CLIP (Balm et al. 1994). The unidentified peaks therefore probably do not represent carp CLIP. Two $\alpha-\mathrm{MSH}$ immunoreactive products were found in these carp larvae, co-eluted with des-acetylated and mono-acetylated $\alpha-\mathrm{MSH}$ respectively. Although no di-acetylated form was found at this stage of development, these findings show that acetylation of $\alpha-\mathrm{MSH}$ is taking place at least $168 \mathrm{~h}$ after fertilisation.

\section{Structural development of the HPI axis}

The results of this study demonstrate that in carp the pituitary-interrenal axis is already functional at the time of hatching (56 h after fertilisation). This conclusion is based on three observations. First, whole-body ACTH $(24 \mathrm{~h}$ after fertilisation), cortisol (36 h after fertilisation), and to a 
lesser extent, $\alpha-\mathrm{MSH}$ levels markedly increased before hatching. Secondly, elevated whole-body cortisol levels were observed in carp embryos before hatching as a result of handling. Thirdly, carp larvae responded to handling stress directly after hatching, indicating that a nonstress-responsive period after hatching is absent. This is the first study to measure concurrently whole-body levels of ACTH, $\alpha-\mathrm{MSH}$ and cortisol during the early development of a freshwater fish and after exposure to handling stress in this period. Previously we showed (Stouthart et al. 1998) that a $48 \mathrm{~h}$ exposure to the toxicant PCB 126 during the embryonic stage induced an increase in whole-body ACTH, $\alpha-\mathrm{MSH}$ and cortisol levels in carp larvae compared with larvae from sham-treated embryos.

The presence of ACTH, $\alpha-\mathrm{MSH}$ and cortisol in unfertilised eggs and the first embryonic stages of teleosts is most likely due to maternal deposition of these hormones in the yolk sac (Feist et al. 1990). In several fish species, plasma cortisol levels are rising during the final stages of vitellogenesis and during ovulation, and cortisol is known to pass easily through cell membranes because of its lipophilicity (Feist et al. 1990). Also the presence of other lipophilic hormones such as thyroid hormones and sex steroids like oestradiol and testosterone have been demonstrated in eggs of teleosts (Feist et al. 1990, De Jesus et al. 1991, De Jesus \& Hirano 1992). However, peptide hormones such as prolactin and growth hormone have also been demonstrated in fish eggs (Lam 1994). A possible reason is that ACTH and $\alpha-\mathrm{MSH}$ are transferred passively with vitellogenin into the eggs during oogenesis, but the typical characteristics of the larval ACTH and $\alpha-\mathrm{MSH}$ immunoreactivities may argue against this. The function of the hormones deposited by the female in the eggs is not yet clear, although the patterns of disappearance of the various hormones from the yolk may reflect the demand of the embryos for these hormones during embryogenesis, until endogenous hormone production starts (Brown \& Bern 1989). Endogenous ACTH and $\alpha-\mathrm{MSH}$ production, as judged from an increase in whole-body hormone content, was detected biochemically $24 \mathrm{~h}$ after fertilisation. Since no literature on whole-body levels of ACTH and $\alpha-\mathrm{MSH}$ in early stages of fish development is available, our results can only be compared with immunohistochemical data. Naito et al. (1993) detected immunoreactive ACTH and $\alpha-\mathrm{MSH}$ in the pituitary of chum salmon (Oncorhynchus keta) 2 weeks before hatching. The number, size and also the intensity of the immunoreactive staining of the ACTH and $\alpha-\mathrm{MSH}$ cells increased gradually during embryonic life, and markedly after hatching (Naito et al. 1993, Saga et al. 1993). These authors found a coordinated development of the adeno- and neurohypophysis. Neuroendocrine fibres, from areas including the preoptic regions, reached the neurohypophysis during the final week of embryonic life, indicating the development of the characteristic hypothalamus-pituitary relationship by the time of hatching. In a study on the early development of rainbow trout (Oncorhynchus mykiss), Saga et al. (1993) found immunoreactive $\alpha-\mathrm{MSH}$ at 18 days after fertilisation (stage 21) and ACTH at 35 days after fertilisation (stage 28) in the pituitary gland; hatching occurred 42 days after fertilisation (stage 29). Both number and immuno-reactivity of the cells increased gradually during embryonic development. In most of these studies the distinction between the production sites of both hormones, in particular in embryos, could not be clearly established, because the ACTH and $\alpha-\mathrm{MSH}$ antibodies used showed some cross-reactivity, and because before hatching the ACTH- and $\alpha-\mathrm{MSH}-$ producing cells are still located in the same area of the pituitary gland. The decrease in whole-body ACTH and $\alpha-\mathrm{MSH}$ during the early embryonic stages indicates the clearance of these hormones. No literature is available on the clearance of ACTH and $\alpha-\mathrm{MSH}$ during early development. Several studies on different fish species showed that, in fertilised eggs, corticosteroids as well as sex steroids and thyroid hormones can be metabolised (De Jesus et al. 1991, De Jesus \& Hirano 1992, Hwang et al. 1992, Hwang \& Wu 1993, Barry et al. 1995, Sampath-Kumar et al. 1995). Importantly, endogenous ACTH and $\alpha-\mathrm{MSH}$ production occurred in the carp embryos before cortisol production had started. After hatching, whole-body ACTH levels decreased slightly but remained relatively stable, while wholebody levels of $\alpha-\mathrm{MSH}$ increased markedly $96 \mathrm{~h}$ after fertilisation.

The rapid decrease in cortisol that we observed during the first stages of embryonic development in carp has also been reported for Japanese flounder, chum salmon, tilapia, rainbow trout and Asian seabass (Lates calcarifer) (De Jesus et al. 1991, De Jesus \& Hirano 1992, Hwang et al. 1992, Hwang \& Wu 1993, Barry et al. 1995, Sampath-Kumar et al. 1995). This points to metabolisation in the embryos of the cortisol of maternal origin. As mentioned above, teleost embryos have been shown to metabolise steroids from the day of fertilisation of the eggs, and we suggest that eggs may utilise maternal cortisol during early development as long as the interrenal gland is not yet functional. Most authors showed that whole-body cortisol levels decreased during the whole course of embryonic development of different species (De Jesus et al. 1991, Hwang et al. 1992, Hwang \& Wu 1993, Barry et al. 1995, Sampath-Kumar et al. 1995), and these authors could not demonstrate endogenous cortisol production before hatching. In contrast, our observations on carp show that the levels of this hormone markedly increased $36 \mathrm{~h}$ after fertilisation, which demonstrates that endogenous production had already started well before hatching. Thus carp is the first species for which endogenous production of ACTH, $\alpha-\mathrm{MSH}$ as well as cortisol has been demonstrated at the embryonic stage. The first indications of endogenous cortisol production in other fish 
species have only been observed after hatching: tilapia after 1 day (Hwang et al. 1992, Hwang \& Wu 1993); rainbow trout after 1 day (Hwang et al. 1992, Barry et al. 1995); milkfish (Chanos chanos) after 3 days (Hwang et al. 1992); Asian seabass after 4 days (Sampath-Kumar et al. 1995); yellowfin bream (Acanthropagrus latus) after 5 days; and Japanese flounder after 15 days (De Jesus et al. 1991).

\section{Functional development of the HPI axis}

Typically, the first signs of cortical tissue in teleosts are observed before hatching (Chester Jones \& Mosley 1980), which is consistent with our finding that whole-body cortisol levels increased within 5 min when carp embryos were stressed. This indicates that a stress response can already be evoked at a very early stage in the life of the carp. However, no evidence was found that the HPI axis of rainbow trout is transiently activated before hatching on handling stress (Pottinger \& Mosuwe 1994, Barry et al. 1995). Our experiments also show that freshly hatched larvae were sensitive to handling. In salmonids this response appears after hatching. In rainbow and brown trout (Salmo trutta) a rise in whole-body corticosteroids in response to handling and confinement could not be observed before larvae reared at $5{ }^{\circ} \mathrm{C}$ were 5 weeks old, and it took 30-60 min to develop (Pottinger \& Mosuwe 1994). Barry et al. (1995) demonstrated doubling of cortisol levels in 2-week-old post-hatch rainbow trout larvae reared at $10{ }^{\circ} \mathrm{C}, 1 \mathrm{~h}$ after $30 \mathrm{~s}$ handling followed by $0{ }^{\circ} \mathrm{C}$ cold shock. These results indicate that the start of the cortisol stress response might be related to the temperature at which the fish eggs and larvae have been reared. Stephens et al. (1997) showed that, in turbot (Scophthalmus maximus) larvae that were kept at $15{ }^{\circ} \mathrm{C}$ and exposed to crude oil, whole-body cortisol levels increased from as early as 2 days after hatching. A response by the HPI axis to a stressor in fish embryos, as demonstrated in our study on carp, is so far unique to fish. In birds, stress responsiveness at first gradually increases but markedly rises just before hatching (Carsia \& Malamed 1989). This is followed by a period of non-responsiveness to stressors, which starts after hatching and lasts for $48 \mathrm{~h}$ (DeKloet et al. 1988). Similarly, in mammals a period of non-responsiveness has been reported immediately after birth. In rats, basal corticosteroid levels decrease dramatically after birth and remain low for 2 weeks, during which time different types of stressor do not elicit increases in circulating glucocorticoid levels as they do in adult animals (DeKloet et al. 1988). We obtained no evidence for a period of non-responsiveness to stressors during the early development of carp. The species differences in HPI development between carp and other species may correlate with the differences in the morphogenetic stages of teleost larvae at the time of hatching (Balon 1981) and may not be solely temperature- dependent. Also, differences between the early life histories of salmonids and carp could relate to the differences observed, since salmonids spend a considerable time period as yolk-sac larvae or alevins within the gravel substrate in which the eggs are laid, whereas cyprinids are free-swimming larvae on hatching. Carp is of interest because its embryonic development is very fast $\left(72 \mathrm{~h}\right.$ at $\left.24^{\circ} \mathrm{C}\right)$, much faster than, for instance, the development of a warm water species such as tilapia (12 days at $26^{\circ} \mathrm{C}$ ) or cold water species such as salmonids (27-29 days at $\left.10^{\circ} \mathrm{C}\right)$.

The cortisol response to handling in carp embryos was observed at a time when ACTH and $\alpha$-MSH production has already started, and, since both hormones have been implicated in the pituitary control of cortisol secretion in fish, one or both may have acted as the cortisol secretagogue in this experiment. In addition to short-term regulation of cortisol, the trophic action of ACTH is also probably involved in the normal development of the interrenal cells (DeKloet et al. 1988). $\alpha-\mathrm{MSH}$ appears to be a less likely cortisol secretagogue at this stage of development, because the most corticotrophic form (di-acetylated $\alpha-\mathrm{MSH}$; Balm et al. 1995) was not present in these larvae. In addition to ACTH and $\alpha-\mathrm{MSH}$, other neuroendocrine factors, such as acetylcholine and atrial natriuretic peptide (Kloas et al. 1994), may be involved because, as in mammals and other teleosts, the control of cortisol release in carp is multifactorial.

Cortisol plays an important role during the early development of fish. Hwang \& Wu (1993) showed that larval tilapia 1 day after hatching increased their wholebody cortisol contents when transferred to $20 \%$ seawater, indicating that at that stage the hormone may be involved in seawater adaptation. In these experiments the survival of cortisol-fed tilapia larvae after transfer from freshwater to $27 \cdot 5 \%$ seawater was significantly higher than that of control larvae. Furthermore Mathiyalagan et al. (1996) showed that immersion of 1-day-old tilapia larvae in a cortisol solution significantly enhanced their growth, while higher concentrations caused retarded growth. Cortisol is an important osmoregulatory hormone for ion regulation in freshwater as well as in seawater fish. An important target for this action are the chloride cells of the gills. Proliferation, differentiation and $\mathrm{Na}^{+} / \mathrm{K}^{+}$-ATPase activity of these cells are stimulated by cortisol (McCormick 1995). Li et al. (1995) showed that the gills of tilapia already have functional chloride cells immediately after hatching. Thus cortisol may already control chloride cell function immediately after hatching. Therefore, in view of the effects of cortisol demonstrated in these early stages, we suggest that transient activation of interrenal cortisol production as the result of stressful stimuli will have major consequences for further development of the fish. 


\section{Acknowledgements}

We thank Mr Jan Peters, Mr Tom Spanings and Mr Tony Coenen for their help and valuable suggestions. This study was supported by EU project EV5 V-CT94-0418.

\section{References}

Balm PHM, Pepels P, Helfrich S, Hovens MLM \& Wendelaar Bonga SE 1994 Adrenocorticotropic hormone in relation to interrenal function during stress in tilapia (Oreochromis mossambicus). General and Comparative Endocrinology 96 347-360.

Balm PHM, Hovens MLM \& Wendelaar Bonga SE 1995 Endorphin and MSH in concert form the corticotropic principle released by tilapia (Oreochromis mossambicus; teleostei) melanotropes. Peptides 16 463-469.

Balm PHM, Rentier-Delrue F, Rand-Weaver M \& Martial JA 1998 Recombinant rainbow trout somatolactin (SL) counteracts stress-associated hypochloremia. Molecular Cellular Endocrinology (In Press).

Balon EK 1981 Saltatory processes and altricial to precocial forms in the ontogeny of fishes. American Zoologist 21 573-596.

Barry TP, Malison JA, Held JA \& Parrish JJ 1995 Ontogeny of the cortisol stress response in larval rainbow trout. General and Comparative Endocrinology 97 57-65.

Bennett HPJ, Brubaker PL, Seger MA \& Solomon S 1983 Human phosphoserine 31 corticotropin $_{1-39}$ isolation and characterisation. Journal of Biological Chemistry 258 8108-8112.

Brown CL \& Bern HA 1989 Thyroid hormones in early development, with special reference to teleost fishes. In Development, Maturation and Senescence of Neuroendocrine Systems: A Comparative Approach, pp 289-306. Eds M Schreibman and C Scanes. New York: Academic Press.

Carsia RV \& Malamed S 1989 The adrenals. In Development, Maturation and Senescence of Neuroendocrine Systems: A Comparative Approach, pp 353-380. Eds M Schreibman and C Scanes. New York: Academic Press.

Chester Jones I \& Mosley W 1980 The interrenal gland in fishes. Part 1. Structure. In General, Comparative and Clinical Endocrinology of the Adrenal Cortex, pp 395-472. Eds I Chester Jones and IW Henderson. London: Academic Press.

De Jesus EG \& Hirano T 1992 Changes in whole-body concentrations of cortisol, thyroid hormones, and sex steroids during the early development of the chum salmon, Oncorhynchus keta. General and Comparative Endocrinology 85 55-61.

De Jesus EG, Hirano T \& Inui Y 1991 Changes in cortisol and thyroid hormone concentrations during early development and metamorphosis in the Japanese flounder, Paralichthys olivaceus. General and Comparative Endocrinology 82 369-376.

DeKloet ER, Rosenfeld P, Van Eekelen JAM, Sutanto W \& Levine S 1988 Stress, glucocorticoids and development. Progress in Brain Research 73 101-120.

Dores RM, Sandoval FL \& McDonald LK 1993 Proteolytic cleavage of ACTH in corticotropes of sexually mature axolotls (Ambystoma mexicanium). Peptides 14 1029-1035.

van Eys GJJM \& van den Oetelaar 1981 Cytological localization of $\alpha-\mathrm{MSH}, \mathrm{ACTH}$ and $\beta$-endorphin in the pars intermedia of the cichlid teleost Sarotherodon mossambicus. Cell and Tissue Research 215 625-633.

Feist G, Schreck CB, Fitzpatrick MS \& Redding JM 1990 Sex steroid profiles of coho salmon (Oncorhynchus kisutch) during early development and sexual differentiation. General and Comparative Endocrinology $80299-313$.

Follénius E, van Dorsselaer A \& Meunier A 1985 Separation and partial characterization by high-performance liquid chromatography and radioimmunoassay of different forms of melanocyte-stimulating hormone from fish (Cyprinidae). General and Comparative Endocrinology 57 198-207.

Hon WK \& Ng TB 1986 Hormones with adrenocorticotropic and opiate-like activities from the carp (Cyprinus carpio) pituitary. Comparative Biochemistry and Physiology 85C 443-448.

Hwang PP \& Wu SM 1993 Role of cortisol in hypo-osmoregulation in larvae of tilapia (Oreochromis mossambicus). General and Comparative Endocrinology 92 318-324.

Hwang PP, Wu SM, Lin JH \& Wu LS 1992 Cortisol content of eggs and larvae of teleosts. General and Comparative Endocrinology 86 189-196.

Kloas W, Reinecke M \& Hanke W 1994 Role of the atrial natriuretic peptide for adrenal regulation in the teleost fish Cyprinus carpio. American Journal of Physiology 267 1034-1042.

Lam TJ 1994 Hormones and egg/larval quality in fish. Journal of the World Aquaculture Society 25 2-12.

Lamers AE, Haenen HEMG, Jenks BG, Balm PHM \& Wendelaar Bonga SE 1991 Regulation of differential release of $\alpha-\mathrm{MSH}$ forms from the pituitary of Oreochromis mossambicus. Journal of Endocrinology 129 179-187.

Lamers AE, Flik G, Atsma W \& Wendelaar Bonga SE 1992 A role for di-acetyl $\alpha-\mathrm{MSH}$ in the control of cortisol release in Oreochromis mossambicus. Journal of Endocrinology 135285 292.

Li J, Eygensteyn J, Lock RAC, Verbost PM, van der Heijden AJH, Wendelaar Bonga SE \& Flik G 1995 Branchial chloride cells in larvae and juveniles of freshwater tilapia Oreochromis mossambicus. Journal of Experimental Biology 198 2177-2184.

McCormick SD 1995 Hormonal control of gill $\mathrm{Na}^{+}, \mathrm{K}^{+}$-ATPase and chloride cell function. In Cellular and Molecular Approaches to Fish Ionic Regulation, pp 285-316. Eds CM Wood and TJ Shuttleworth. San Diego: Academic Press.

Mathiyalagan A, Reddy PK \& Lam TJ 1996 Effects of cortisol on growth and development in tilapia larvae, Oreochromis mossambicus. Fish Physiology and Biochemistry 15 453-458.

Naito N, De Jesus EG, Nakai Y \& Hirano T 1993 Ontogeny of pituitary cell-types and the hypothalamo-hypophysial relationship during early development of chum salmon, Oncorhynchus keta. Cell and Tissue Research 272 429-437.

Oyen FGF, Camps LECMN \& Wendelaar Bonga SE 1991 Effects of acid stress on the embryonic development of the common carp (Cyprinus carpio). Aquatic Toxicology 19 1-12.

Perez FM, Schwartz J \& Rose JC 1997 Developmental changes in ovine corticotrophs in vitro. Endocrinology 138 916-921.

Pottinger TG \& Mosuwe E 1994 The corticosteroidogenic response of brown and rainbow trout alevins and fry to environmental stress during a 'critical period'. General and Comparative Endocrinology 95 350-362.

Saga T, Oota Y, Nazaki M \& Swanson P 1993 Salmonoid pituitary gonadotrophs. III. Chronological appearance of GTH I and other adenohypophysial hormones in the pituitary of the developing rainbow trout (Oncorhynchus mykiss irideus). General and Comparative Endocrinology 92 233-241.

Sampath-Kumar R, Byers RE, Munro AD \& Lam TJ 1995 Profile of cortisol during the ontogeny of the Asian seabass, Lates calcarifer. Aquaculture 132 349-359.

Stephens SM, Alkindi AYA, Waring CP \& Brown JA 1997 Corticosteroid and thyroid responses of larval and juvenile turbot exposed to the water-soluble fraction of crude oil. Journal of Fish Biology 50 953-964.

Stouthart AJHX, Huijbregts MAJ, Balm PHM, Lock RAC \& Wendelaar Bonga SE 1998 Endocrine stress response and abnormal development in carp (Cyprinus carpio) larvae after exposure of the embryos to PCB 126. Fish Physiology and Biochemistry (In Press). 
Tran TN, Fryer JN, Bennett HPJ, Tonon MC \& Vaudry H 1989 TRH stimulates the release of POMC-derived peptides from goldfish melanotropes. Peptides 10 835-841.

Wendelaar Bonga SE 1997 The stress response in fish. Physiological Review 77 591-625.

Yamano K, Tagawa M, De Jesus EG, Hirano T, Miwa S \& Inui Y 1991 Changes in whole-body concentrations of thyroid hormones and cortisol in metamorphosing conger eel. Journal of Comparative Physiology B 161 371-375. van Zoest ID, Heijmen PS, Cruijsen PMJM \& Jenks BG 1989 Dynamics of background adaptation in Xenopus laevis: Role of catecholamines and melanophore stimulating hormone. General and Comparative Endocrinology 76 19-28.

Received 15 July 1997

Revised manuscript received 17 October 1997 Accepted 11 November 1997 